\title{
Effect of feeding biotin on milk production and hoof health in lactating dairy cows: A quantitative assessment
}

\author{
I. J. Lean ${ }^{1}$ and A. R. Rabiee \\ SBScibus, PO Box 660, Camden 2570, New South Wales, Australia
}

\section{INTRODUCTION}

Although ruminants produce biotin as a result of bacterial fermentation, the requirements for biotin and other B-group vitamins in cattle have been reevaluated (Girard, 1998). Biotin is essential for ruminants and studies have been conducted on biotin synthesis, absorption, and balance in lactating and nonlactating cattle (Miller et al., 1986; Frigg et al., 1993, 1994; Kluenter et al., 1993; Steinberg et al., 1995). Biotin is a cofactor for microbial enzymes involved in propionic acid synthesis (Baldwin and Allison, 1983) and is also present in carboxylase-containing enzymes critical to gluconeogenesis and other metabolic roles in mammals (Mock, 2005).

In vivo studies (Miller et al., 1986; Santschi et al., 2005a,b; Schwab et al., 2006) found low or even negative apparent ruminal synthesis of biotin. However, Zinn et al. (1987) estimated a positive apparent synthesis of biotin in beef cattle. Diets containing more than $50 \%$ of DM as grain decreased ruminal synthesis of biotin in vitro compared with diets containing more forage (Abel et al., 2001). Bentley et al. (1954) and Milligan et al. (1967) showed that biotin supplementation increased fiber digestion in vitro, and that ruminal bacteria also require biotin for propionate production. Propionate production by mixed ruminal bacteria was reduced in vitro when biotin was not included in the culture media (Bentley et al., 1954; Milligan et al., 1967). These studies suggest that supplemental dietary biotin may increase fiber digestion or increase propionate production, thereby providing additional nutrients that may be partitioned to milk production by the cow. Consequently, interest exists in milk production responses to supplemental biotin, especially in cattle fed diets containing substantial amounts of concentrate. However, milk production responses to supplemental biotin have not consistently been significant, suggesting the need to quantitatively evaluate responses and to examine the sources of variation in responses.

Many studies have investigated the biological effects of biotin on hoof health, including keratin protein synthesis and formation of the intercellular cement, which influence horn formation of the hoof, hoof strength, and claw integrity (Whitehead, 1988; Sarasin, 1994;

Received August 3, 2010.

Accepted October 30, 2010.

${ }^{1}$ Corresponding author: ianl@sbscibus.com.au 
Hochstetter, 1998; Fitzgerald et al., 2000; Hedges et al., 2001; Koester et al., 2002). There were, however, limited randomized controlled studies on the clinical effect of biotin supplementation to improve hoof health and reduce the risk of lameness in dairy cows.

This study reviewed and collated papers and reports on biotin. Our aim was to quantify the effects of supplementation on milk production and hoof disorders to improve the precision of point estimates derived from pooled data, answer questions not posed by the individual studies identified by the literature search, settle controversies arising from apparently conflicting studies, or generate new hypotheses. We also explored sources of heterogeneity among production studies and evaluated the presence of publication bias.

\section{MATERIALS AND METHODS}

\section{Literature Search}

The literature search, using PubMed, Google Scholar, Agricola, Science Direct, Scirus, and CAB, contact with workers in the field, and investigation of references in papers identified yielded 205 publications on biotin. The following key words in different combinations were used for our search: transition period, milking period, prepartum, peripartum, postpartum, biotin, vitamin B complex, cattle, cow, dairy, management, milk yield, milk composition, dry matter intake, supplement, hoof health. A total of 34 research papers and reports (journal articles, published abstracts, and reports) had milk production or hoof health data, or both. Of these, 6 randomized clinical studies with production data, containing 11 comparisons, provided suitable information and were considered in the meta-analysis. Eight studies with hoof health information that did not meet the selection criteria for a meta-analysis, were subsequently evaluated to determine the direction of effect. A list of publications reviewed for the study is provided in Table 1.

\section{Inclusion and Exclusion Criteria}

Studies were included or excluded in this study based on criteria developed by the authors. Quality assessment criteria included randomization of study groups, blinding to treatment application and analysis of data, statistical analysis, and comparability of treatment groups at entry to each trial. Trials were included in the analysis if the animals utilized were lactating dairy cows and if they reported an adequate description of randomization processes; sufficient data to determine the effect size for production outcomes (e.g., the number of cows in each treatment and control group); a

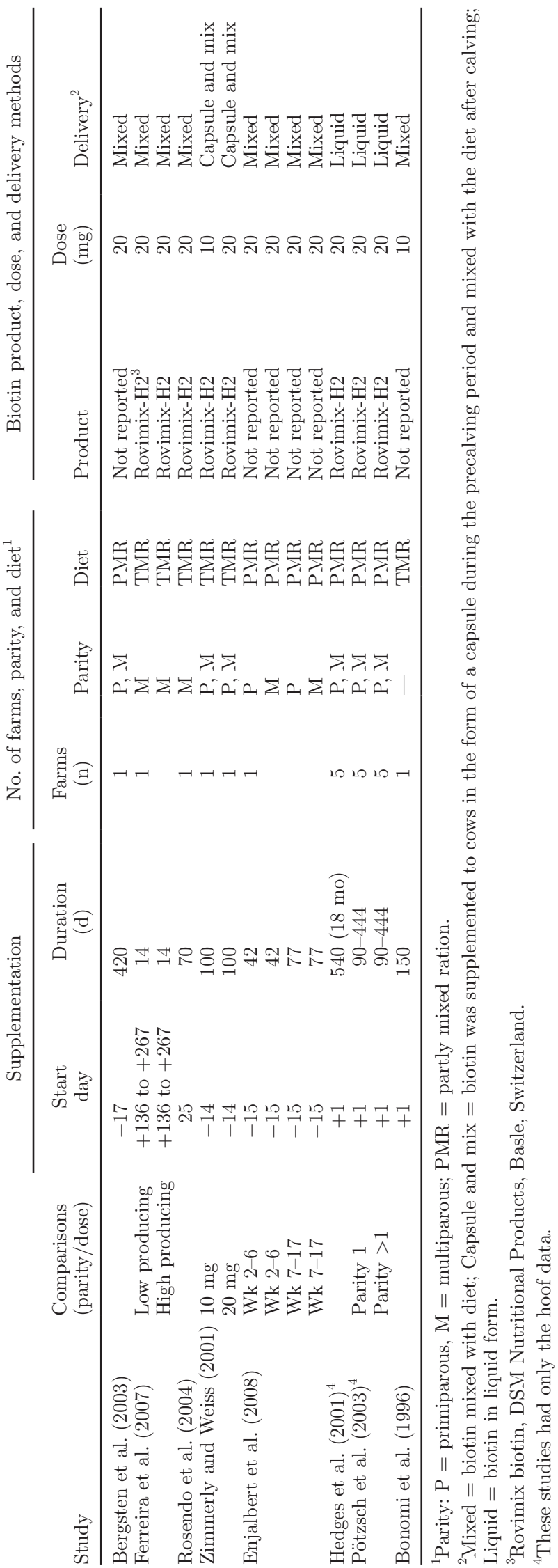


measure of effect amenable to effect size analysis for continuous data [e.g., standardized mean difference (SMD)] and the rate data [e.g., risk ratio ( $\mathbf{R R})]$; a measure of variance (SE or SD) or $P$-value, or both, for each effect estimate or treatment and control comparisons; and the number of cows and incidence of hoof disorders in biotin-supplemented and control groups.

In total, 26 studies were excluded from analysis. Studies that failed to meet the essential criteria of the randomized controlled trial included reviews and studies that had no milk production or hoof health data or had positive controls; the excluded studies are listed in the Appendix. Crossover and Latin square studies were also excluded from the meta-analysis. The gold standard for inclusion in a meta-analysis is a randomized clinical trial, and crossover and Latin square studies provide less rigorous evidence. We exclude Latin square and crossover designs because the randomized, controlled trial is at present the unchallenged source of the highest standard of evidence used to guide clinical decision making (Lavori and Kelsey, 2002). Other reasons for the exclusion of crossover and Latin square studies were the potential for carryover effects (Lean et al., 2009) and the small sample size of these studies that often had multiple phases. Most of these studies reported a standard error or standard deviation of the means overall rather than for each period; of those that reported the measure of variance, it was not always clear how these measures of variance were estimated. Finally, if these studies are included in a meta-analysis, the data set may become heterogeneous because the design of these studies inherently differs from the randomized, controlled trial studies.

\section{Data Extraction}

A total of 6 studies (11 comparisons) with production data met the eligibility criteria for meta-analysis. A total of 3 eligible studies (4 comparisons) with hoof health incidence data were available, but this was insufficient to justify a meta-analysis. The other hoof health studies ( $\mathrm{n}=9$ papers) reported various hoof disorders or inconsistent measurement metrics (prevalence and incidence), or did not have adequate information to be included in the meta-analysis.

The extracted data also included number of cows in control and treatment groups, measures of variance of responses (SE or $\mathrm{SD}$ ), and $P$-values. Other information extracted from relevant papers were duration of treatment before and after calving, parity, breed, type and dose of biotin, delivery method of supplementation, and types of diets. A summary of studies and variables measured is given in Table 1. Papers included in this study reported that Holstein-Friesian cows were enrolled, no bST was used, cows were milked twice daily except in one study (Rosendo et al., 2004), and stated the vitamin and minerals that were part of the diet.

\section{Statistical Analysis}

A meta-analysis was conducted on the extracted production outcomes using Stata (Intercooled Stata v.11, StataCorp, College Station, TX).

Continuous Data. Continuous data were analyzed using SMD, which is also called effect size (ES), in which the difference between treatment and control groups means was standardized using the standard deviations of control and treatment groups. The SMD estimates were pooled using the methods of Cohen (1988) for the fixed effect and DerSimonian and Laird (1986) for the random effects models. If the paper reported separate estimates of measure of variance (SE or SD) for each group, these were recorded as such. If the studies reported a common SE or SD, the estimate was used for both control and treatment groups. If the study only reported a Z-statistic or $P$-value, estimates of SE or SD were computed using the number of cows in each group. For studies that only reported a $P$-value less or equal to a given value (e.g., $P<$ or $>0.05$ ), then the given value was used, and $P$-value and SE were computed similarly to the methods described above. For studies that only reported a nonsignificant effect, $P$-values of $0.15,0.3$, and 0.5 were assigned and compared as described by Sanchez et al. (2004). The $P$-value that produced the smallest estimate of overall SMD was selected for the calculation of the standard error. Fixed and random effects models were conducted for each production outcome to estimate the effect size, $95 \%$ CI, and statistical significance of SMD.

Forest Plots. The effects of biotin on production performance of lactating dairy cows are displayed in the forest plots, using the estimated SMD of the included studies (Figure 1). Points to the left of the line represent a reduction in the trait, whereas points to the right of the line indicate an increase in the variable. Each square represents the mean effect size for that study. The upper and lower limits of the line connected to the square represent the upper and lower 95\% CI for the effect size. The size of the square reflects the relative weighting of the study to the overall effect size estimate, with larger squares representing greater weight. The dotted vertical line represents the overall effect size estimate. The diamonds at the bottom represent the $95 \%$ CI for the overall estimates of fixed effect (using inverse variance procedures) and random effects (DerSimonian and Laird, 1986) models. The solid ver- 


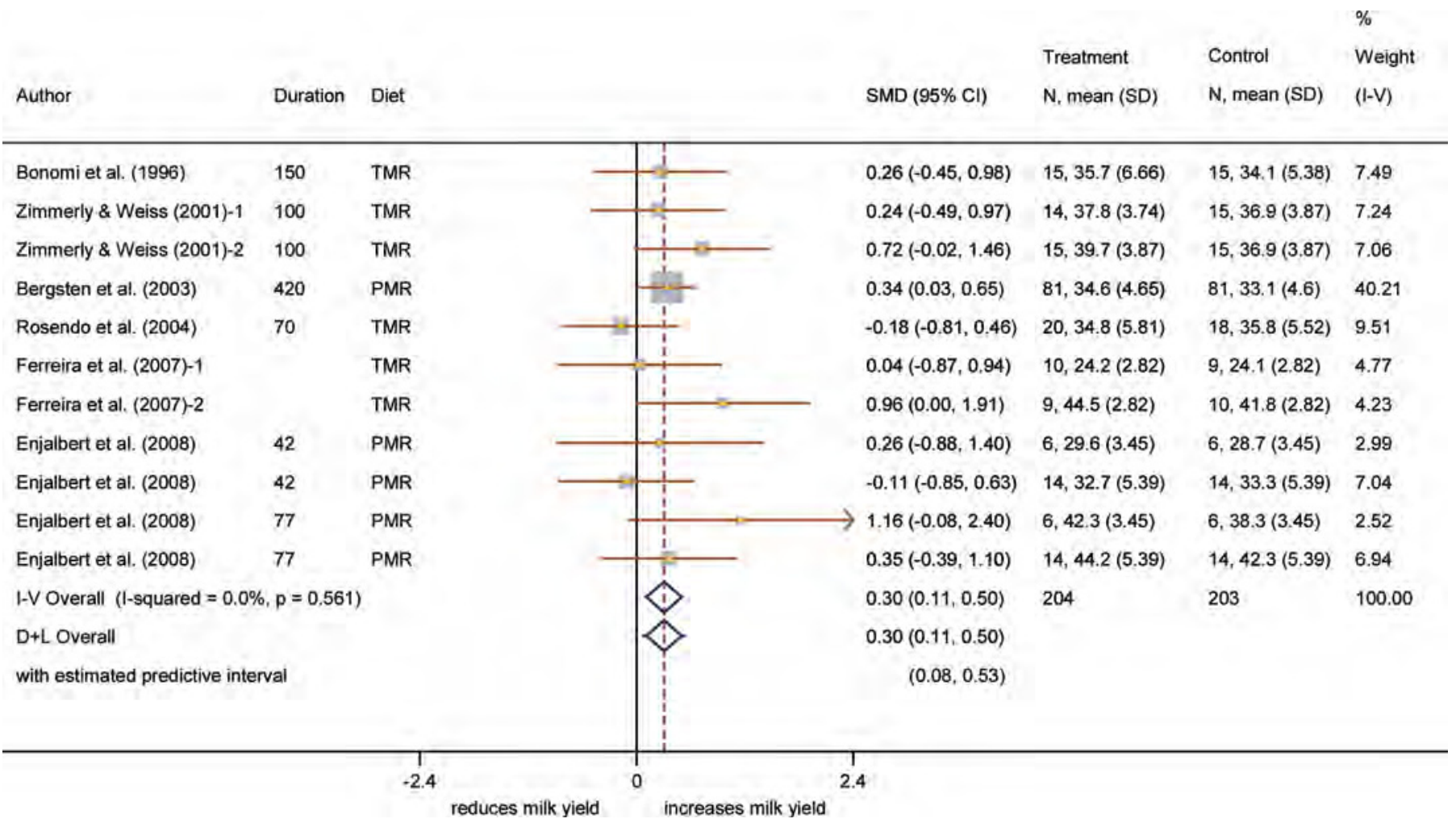

Figure 1. Forest plot of standardized mean difference (SMD) and their 95\% CI and weights for individual trials determined from the results of 11 comparisons of milk production of cows supplemented with biotin versus other cows. Box sizes are proportional to the inverse variance of the estimates. Summary estimates of treatment effects (diamonds) are shown using (1) a fixed effects approach (I-V specifies a fixed effect model using the inverse variance method), (2) a random effects approach (D+L specifies a random effects model using the method of DerSimonian and Laird, 1986), and (3) the predicted interval of a future trial, with the estimate of heterogeneity being taken from the inverse variance fixed effect model. PMR = partial mixed ration. Color version available in the online PDF.

tical line represents a mean difference of zero or no effect. The first author and year of the publication are provided under "Study."

Weighted mean differences (WMD) are estimated using the mean difference between biotin-supplemented and control groups, and weights of number of observations, where weights were inversely proportional to the variance of observations. Typically, the observations represent averages and the weights are the number of elements that give rise to the average.

Hoof Data. Because of the lack of adequate studies that examined any single hoof lesion, lack of consistent definition of hoof lesions between studies, lack of raw data (number of affected and not affected in both groups), and lack of consistency between papers on hoof health measurements (e.g., incidence, prevalence), we were unable to assess these data quantitatively. Only 3 hoof studies met all study criteria. Consequently, the hoof health studies were only assessed to determine the potential trend of effect and justification of the need for further investigation.
Assessment of Heterogeneity. Variations among the trial-level SMD were assessed using a chi-squared $(\mathbf{Q})$ test of heterogeneity. We used an $\alpha$-level of 0.10 because of the relatively poor power of the $\chi^{2}$ test to detect heterogeneity among small numbers of trials (Egger and Davey Smith, 2003). Heterogeneity of results among the trials was quantified using the $I^{2}$ statistic (Higgins and Thompson, 2002; Higgins et al., 2003). Negative values of $I^{2}$ were assigned a value of zero; consequently, the value $I^{2}$ lies between 0 and $100 \%$. An $I^{2}$ value $>50 \%$ may be considered indicative of substantial heterogeneity.

Meta-Regression. Meta-regression is a technique that can formally test whether evidence exists of different effects in different subgroups of trials (Knapp and Hartung, 2003). Meta-regression analyses were used to explore the source of heterogeneity of response, using the individual ES for each trial as the outcome and the associated standard error as the measure of variance. It is appropriate to use meta-regression to explore sources of heterogeneity even if an initial overall test for het- 
Table 2. Standardized mean difference (SMD), significance, weighted mean difference, and heterogeneity of production outcomes

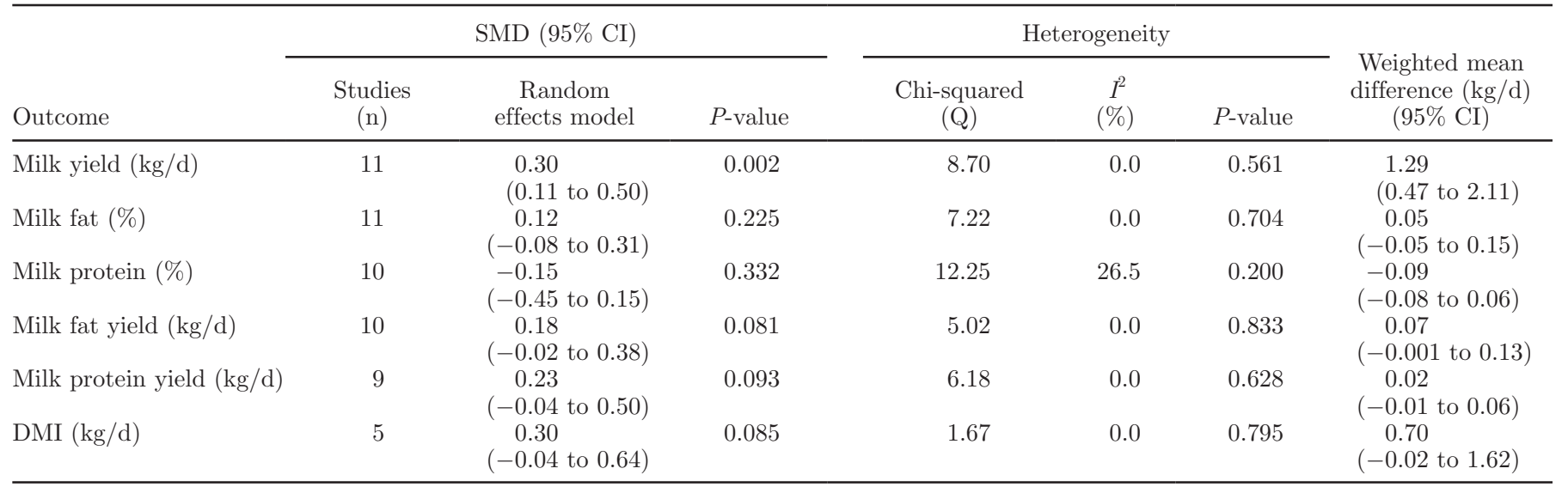

erogeneity is nonsignificant (Thompson and Higgins, 2002). The chi-squared test often has low power (Hardy and Thompson, 1998) and therefore a nonsignificant result does not reliably identify lack of heterogeneity. Furthermore, the test is for general over-dispersion of trial results, and does not address whether heterogeneity relates to particular covariates. A meta-regression was conducted to explore whether the outcomes were influenced by start time (before or after calving), duration of treatment before and after calving, parity of cows in the study (multiparous herds vs. mixed herds), bST treatment, or delivery method (mixed with diet, in a liquid form, or capsule).

Meta-regression analysis was conducted by first screening individual variables using a $P$-value of $\leq 0.20$. All variables with $P$-value of $\leq 0.20$ were entered into a backward stepwise weighted meta-regression, until all remaining variables were significant at $P<0.05$.

Publication Bias. The presence of publication bias is commonly investigated using funnel plots. A funnel plot is a simple scatter plot of the intervention effect estimates from individual studies against some measure of each study's size or precision. It is commonly presented as a plot of the effect estimates on the horizontal scale, and the measure of variance on the vertical axis. The name "funnel plot" arises from the fact that precision of the estimated intervention effect increases as the size of the study increases. Effect estimates from small studies will therefore scatter more widely at the bottom of the graph, with the spread narrowing among larger studies. In the absence of bias, the plot should approximately resemble a symmetrical (inverted) funnel. If bias exists, for example, because smaller studies without statistically significant effects remain unpublished, this will lead to an asymmetrical appearance of the funnel plot with a gap in a bottom corner of the graph. In this situation the effect calculated in a meta-analysis will tend to overestimate the intervention effect (Egger et al., 1997). The more pronounced the asymmetry, the more likely it is that the bias will be substantial.

Contour-Enhanced Funnel Plots. Contourenhanced funnel plots have been proposed by Peters et al. (2008) to include contour lines corresponding to the statistical significance $(P=0.01,0.05,0.1)$. This approach allows the statistical significance of study estimates and areas in which studies are perceived to be missing to be considered. The contour-enhanced funnel plots may help to differentiate asymmetry caused by publication bias from that due to other factors. For example, if studies appear to be missing in areas of statistical nonsignificance, this adds credence to the possibility that the asymmetry is caused by publication bias. Conversely, if the supposed missing studies are in areas of higher statistical significance, this suggests that the observed asymmetry may be more likely caused by factors other than publication bias; for example, variable study quality or a failure to publish findings that were not statistically significant.

Hoof Health Data. Due to substantial amounts of missing information, inconsistencies in reporting hoof lesions in different studies/trials, measures of outcome (incidence vs. prevalence), cattle used (beef vs. dairy), units of observation (animal vs. herd), and doses of biotin, it was not appropriate to conduct a full metaanalysis on hoof data. However, the direction of the effect of biotin in supplemented cattle was assessed by comparing the number of studies with positive and negative outcomes.

\section{RESULTS AND DISCUSSION}

Several studies and reviews (reports and abstracts) failed to provide sufficient information on production and hoof health data. We critically reviewed all the 

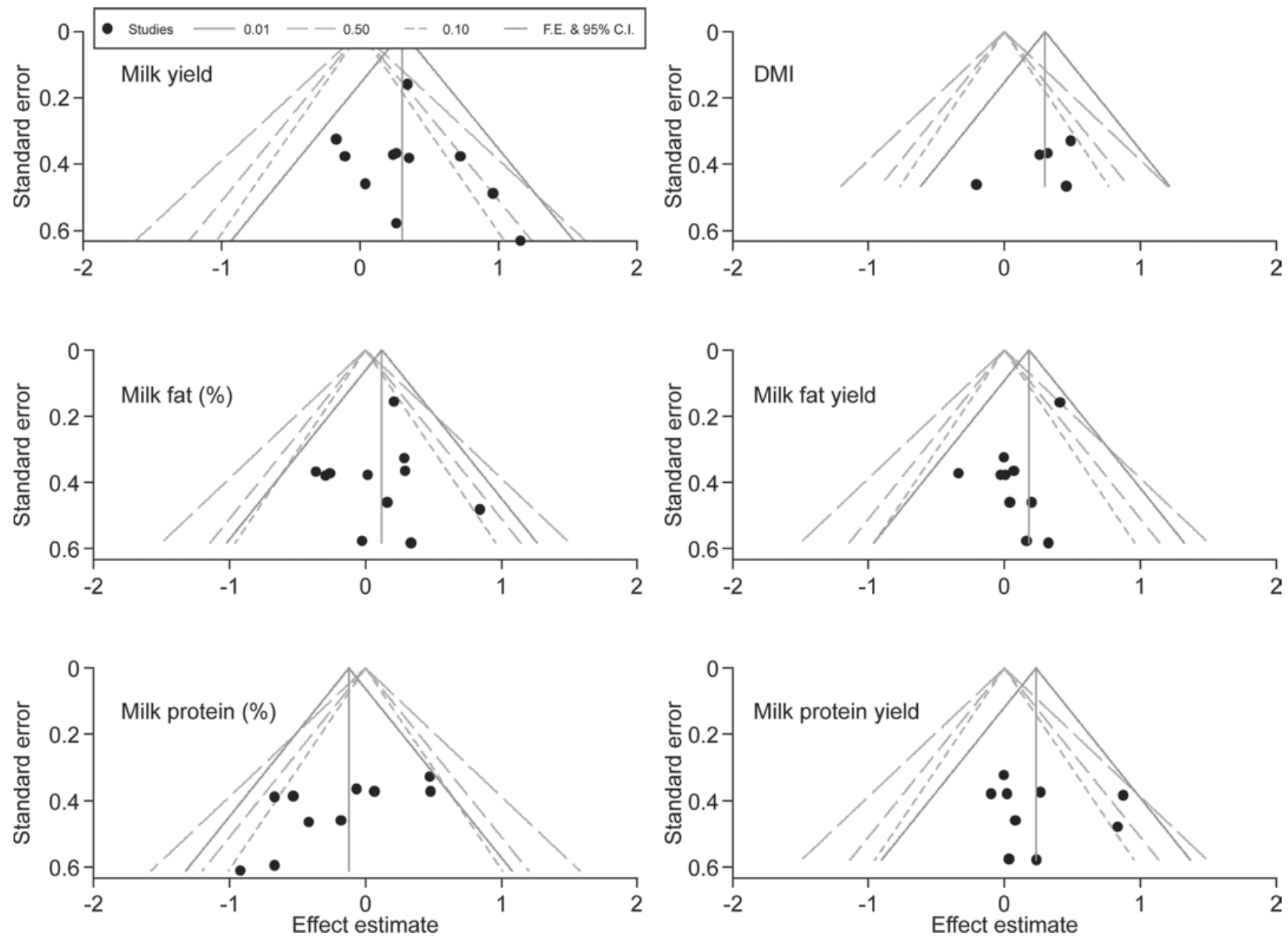

Figure 2. Contour-enhanced funnel plots of production data and DMI for cows supplemented with biotin. Levels of significance for studies (-) within the gray broken lines are $0.01,0.05$, and $0.10 ; \mathrm{FE}=$ fixed effect.

provided information and reports, and summarized the findings on each study in Table 1. A total of 34 studies investigated the effects of biotin on production performance and hoof health in lactating dairy cows. Of these, 26 studies were excluded for various reasons. Of the 8 remaining, 6 were used in meta-analyses of production outcomes, and 3 studies provided only hoof-health data and were insufficient to justify a meta-analysis of hoofhealth outcomes.

\section{Production Outcomes}

A summary of 6 studies containing 11 comparisons with biotin and milk production results is presented in Table 2. Some studies contained a summary of a single trial, whereas others studies reported multiple comparisons such as different doses of biotin or parities of cattle. The effect size analysis of biotin treatment on milk production is presented in Figure 1. An increase in milk production of biotin-supplemented cows was observed ( $\mathrm{ES}=0.30 ; 95 \% \mathrm{CI}=0.11$ to $0.51 ; P=0.002$; Figure 1) with no significant evidence of heterogeneity $\left(I^{2}=0.0 \%, P=0.561\right.$; Table 2$)$. The small number of studies included in the meta-analysis may not allow an accurate determination of the effects of starting time of supplementation (before or after calving) or duration of supplementation before and after calving on the milk production response to biotin. The limited number of studies of the effects of biotin on milk production also makes it difficult to accurately evaluate the presence of publication bias using funnel plots; however, it is possible that negative studies with a high standard error were missing from the milk production data (Figure 2 ). The milk production response to biotin was quite large, being $1.3 \mathrm{~kg} / \mathrm{d}$ per cow. The milk responses were largely observed with diets based on corn silage and 


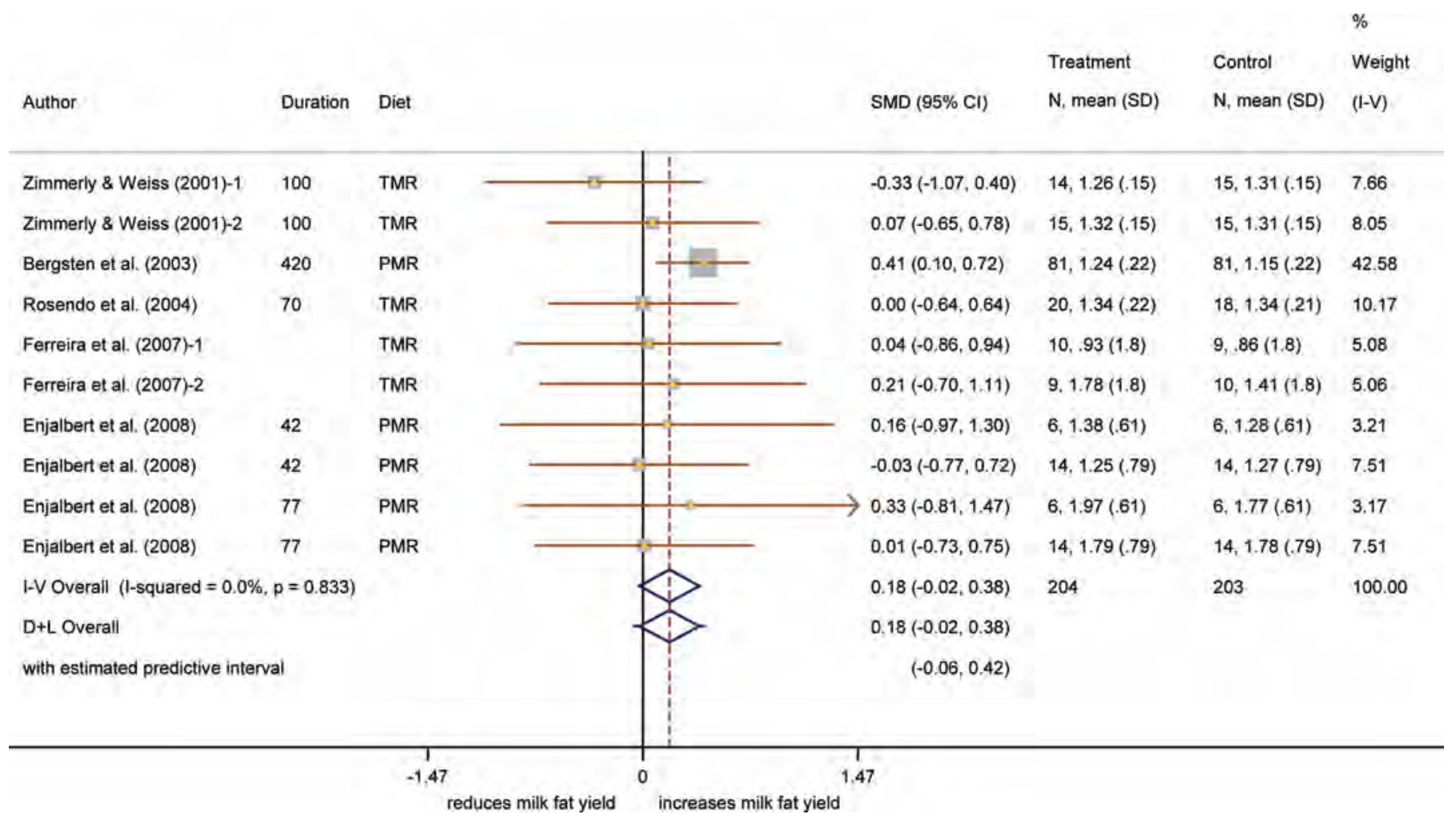

Figure 3. Forest plot of standardized mean difference (SMD) and their $95 \%$ CI and weights for individual trials determined from the results of 10 comparisons of milk fat production of cows supplemented with biotin versus other cows. Box sizes are proportional to the inverse variance of the estimates. Summary estimates of treatment effects (diamonds) are shown using (1) a fixed effects approach (I-V specifies a fixed effect model using the inverse variance method), (2) a random effects approach ( $\mathrm{D}+\mathrm{L}$ specifies a random effects model using the method of DerSimonian and Laird, 1986), and (3) the predicted interval of a future trial, with the estimate of heterogeneity being taken from the inverse variance fixed effect model. $\mathrm{PMR}=$ partial mixed ration. Color version available in the online PDF.

alfalfa as the basal forages in TMR diets. Responses were homogeneous across the range of study designs used. No significant effects of stage of lactation, dose of biotin, duration of supplementation, or type of diet were found on responses. However, it should be noted that relatively few studies were analyzed and the statistical power to investigate some of these sources of variation in study design was limited. Consequently, some caution should be applied to extrapolating these responses to all diet and management systems.

Milk fat percentage did not differ between biotin-fed and control cows (ES $=0.12,95 \%$ CI: -0.08 to $0.31 ; P$ $=0.225)$. Milk fat yield $(\mathrm{kg} / \mathrm{d})$ tended to be greater in biotin-fed cows (ES $=0.18,95 \%$ CI: -0.02 to $0.38 ; P$ $=0.081$, Figure 3). No evidence of significant heterogeneity in milk fat percentage and yield responses was found (Table 2). Meta-regression analysis showed that fat percentage results were not influenced by duration of treatment before and after calving, delivery method of biotin, parity, or other factors. Little evidence of publication bias was found in milk fat percentage data, but some evidence of publication bias was observed in milk fat yield outcomes (Figure 2). Small studies that reported a reduction in milk fat yield were more likely to be published than small studies with an increase in milk fat yield. Because of the small sample size, this finding should be interpreted with caution.

Milk protein percentage did not differ between biotin-fed and control cows (ES for protein $(\%)=-0.15$, $95 \%$ CI: -0.45 to $0.15 ; P=0.332$ ), and milk protein yield $(\mathrm{kg} / \mathrm{d})$ tended to be greater in biotin-fed cows (ES for protein yield $=0.23,95 \%$ CI: -0.04 to $0.50 ; P=$ 0.093 , Figure 4). Responses to biotin treatment for milk protein percentage and yield data (Table 2) were homogeneous. Meta-regression analysis showed that milk protein percentage results may be influenced by diet [coefficient: $-0.78 \pm 0.28, P=0.023$; TMR (reference group) vs. partial mixed ration (PMR)]. The effect of biotin supplementation on milk protein percentage appeared to be greater in cows fed a TMR diet compared with those on a PMR diet. Due to the small number studies in the subgroups (TMR vs. PMR), these results require further validation. Evidence was also found of publication bias in milk protein percentage and yield. 


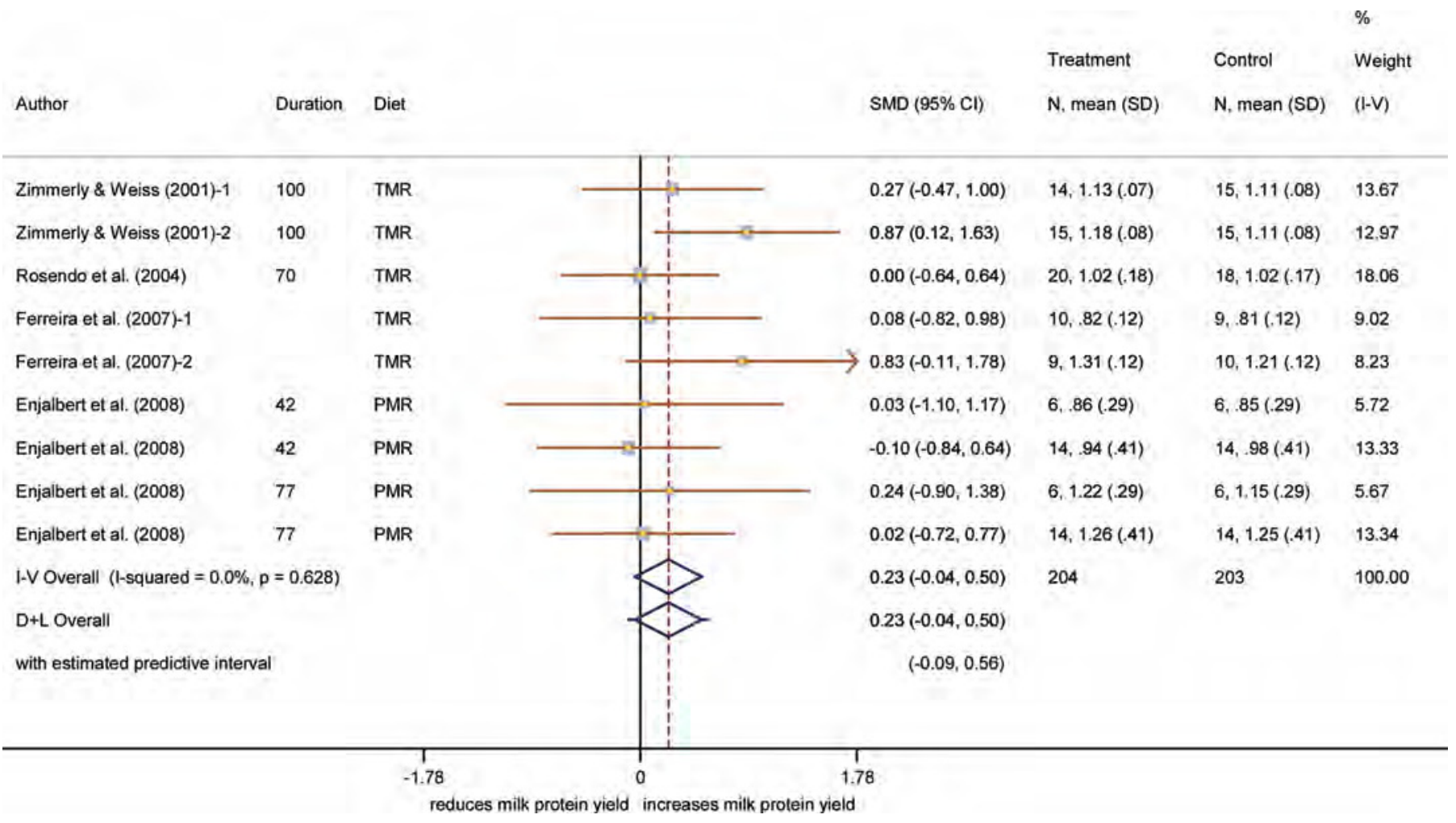

Figure 4. Forest plot of standardized mean difference (SMD) and their $95 \%$ CI and weights for individual trials determined from the results of 9 comparisons of milk protein production of cows supplemented with biotin versus other cows. Box sizes are proportional to the inverse variance of the estimates. Summary estimates of treatment effects (diamonds) are shown using (1) a fixed effects approach (I-V specifies a fixed effect model using the inverse variance method), (2) a random effects approach (D+L specifies a random effects model using the method of DerSimonian and Laird, 1986), and (3) the predicted interval of a future trial, with the estimate of heterogeneity being taken from the inverse variance fixed effect model. $\mathrm{PMR}=$ partial mixed ration. Color version available in the online PDF .

Small studies that reported a reduction in milk protein percentage and milk protein yield may have been more likely to be published than small studies with an increase in milk protein percentage and milk protein yield; again the small sample size suggests that this finding should be interpreted with caution. Milk fat percentage and yield were increased, but not significantly, by treatment. The increase in milk fat percentage did not approach significance, but milk fat yield tended to increase, a result consistent with milk production responses. Similarly, milk protein yield tended to increase, but milk protein percentage was lower with treatment, although not significantly so. It is yet to be determined whether effects of biotin on production are solely mediated by increased feed intake or by increased efficiency of production. The findings support studies that suggest a need for inclusion of biotin in lactating cow diets.

Daily DMI $(\mathrm{kg} / \mathrm{d})$ in cows supplemented ( $\mathrm{n}=5 \mathrm{com}-$ parisons) with biotin tended to be greater than that in the control cows $(\mathrm{ES}=0.30 ; 95 \% \mathrm{CI}=-0.04$ to 0.64 ; $P=0.085)$. No evidence of significant heterogeneity $\left(I^{2}\right.$
$=0.0 \%, P=0.795$; Table 2) was found among studies. The small sample size of the DMI data indicated that it was not appropriate to conduct a meta-regression or examine the presence of publication bias (Figure 2). No significant association was found between the effect size of biotin on milk production and DMI (coefficient: 0.53, $95 \% \mathrm{CI}=0.24$ to $3.48 ; P=0.604)$.

The production responses to biotin were consistently positive, supporting studies that suggest lactating cows require supplementation with B vitamins (Girard, 1998) and studies showing low or even negative apparent ruminal synthesis of biotin (Miller et al., 1986; Santschi et al., 2005a,b; Schwab et al., 2006).

\section{Hoof Health}

Very few studies were available that met the rigorous standards needed for meta-analytic evaluation. All studies that examined the effect of biotin on hoof health are provided in Table 3. It was difficult to obtain some of the original reports or papers and only limited data were given in the abstracts. Our assessments of all 
BIOTIN IN DAIRY CATTLE

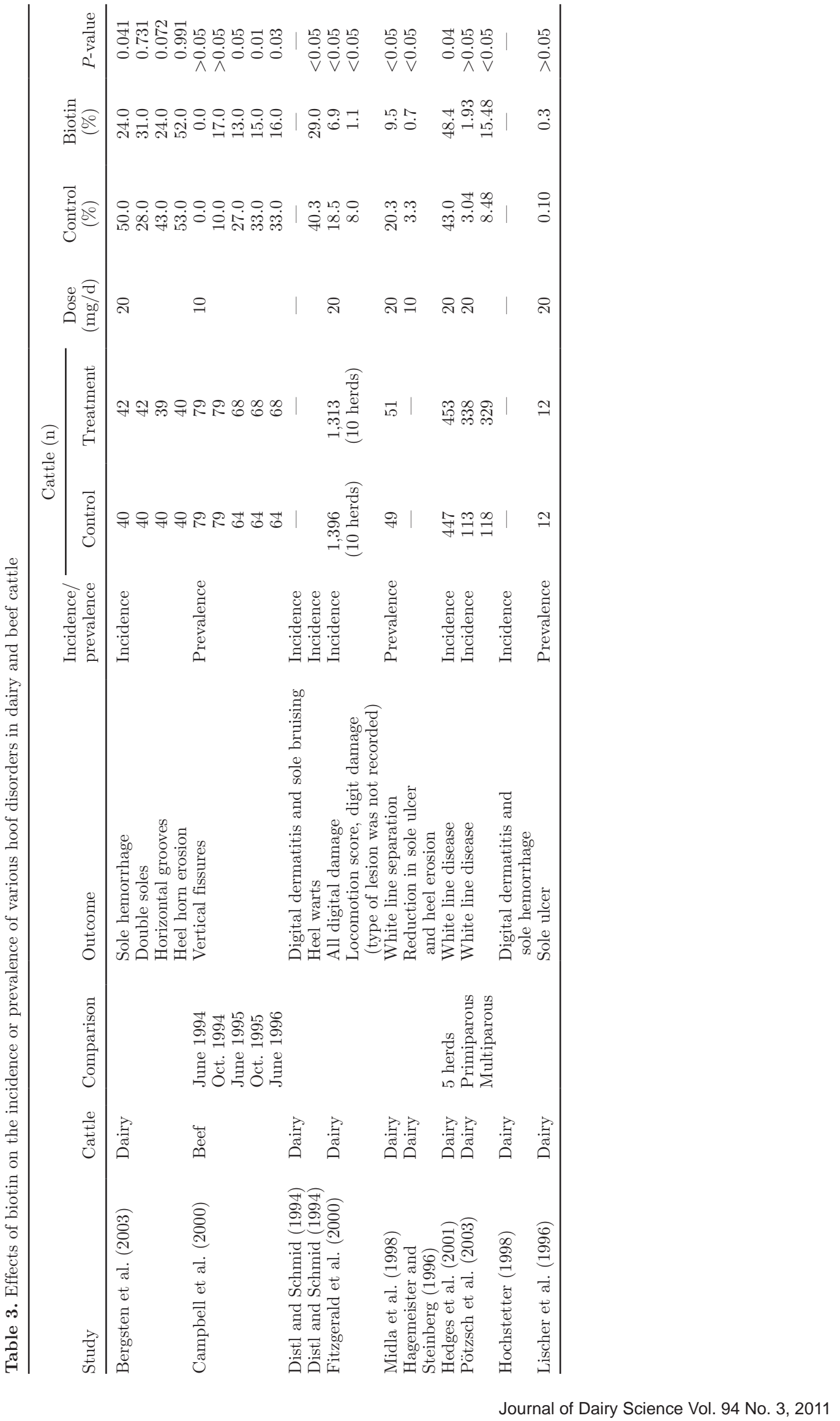


compliant and noncompliant comparisons from which data could be obtained showed that the direction of effect with biotin supplementation was consistently and often, significantly, positive. Many of the studies reported positive biological effects of biotin treatment on hoof strength (Distl and Schmid, 1994; Hagemeister and Steinberg, 1996; Midla et al., 1998; Campbell et al., 2000; Fitzgerald et al., 2000; Hedges et al., 2001; Bergsten et al., 2003; Pötzsch et al., 2003). The marked inconsistency of study designs and study outcomes used to evaluate the effects of biotin on hoof health prevented the use of meta-analytic methods on these data. In contrast to the milk data, a large range of diets and management systems was represented in the lameness studies. These findings support contentions that dairy cows increase milk production following supplementation with biotin. More studies, using consistent study designs and definitions of hoof disorder, are needed to quantify the effects of biotin on lameness, in general, and on specific causes of lameness.

\section{CONCLUSIONS}

This experiment provided quantitative estimates of the milk and milk solids production responses to biotin. The ES estimates can be compared with other treatments to rank different interventions in lactating cattle. The study also provided an exploration of sources of variation in studies that may have influenced responses.

\section{ACKNOWLEDGMENTS}

This study was funded by DSM, Wagga Wagga, New South Wales, Australia.

\section{REFERENCES}

Abel, H., B. Schroder, P. Lebzien, and G. Flachowsky. 2006. Effects of defaunation on fermentation characteristics and biotin balance in an artificial rumen- simulation system (RUSITEC) receiving diets with different amounts and types of cereal. Br. J. Nutr. 95:99-104.

Abel, H., I. Immig, C. Da Costa Gomez, and W. Sternberg. 2001. Effect of increasing dietary concentrate levels on microbial biotin metabolism in the artificial rumen simulation system (RUSITEC). Arch. Tierernahr. 55:371-376.

Baldwin, R. L., and M. J. Allison. 1983. Rumen metabolism. J. Anim. Sci. 57:461-477.

Bentley, O. G., R. R. Johnson, S. Vanecko, and C. H. Hunt. 1954. Studies on factors needed by rumen microorganisms for cellulose digestion in vitro. J. Anim. Sci. 13:581-593.

Bergsten, C., P. R. Greenough, J. M. Gay, W. M. Seymours, and C. C. Gay. 2003. Effects of biotin supplementation on performance and claw lesions on a commercial dairy farm. J. Dairy Sci. 86:39533962 .

Bonomi, A., A. Quarantelli, A. Sabbioni, and P. Superchi. 1996. L'integrazione delle razioni per le bovine da latte con biotina in formua rumino-protetta. Effetti sull'efficienza produttiva e riproduttiva (contributo sperimentale). Le Rivista di Scienza dell'Altimentazione 25:49-68.

Bunge, G. A. 2006. The effect of supplemental biotin in dairy cow diets on forage fermentation characteristics. MS Thesis. University of Stellenbosch, Germany.

Campbell, J. R., P. R. Greenough, and L. Petrie. 2000. The effects of dietary biotin supplementation on vertical fissures of the claw wall in beef cattle. Can. Vet. J. 41:690-694.

Cohen, J. 1988. Statistical Power Analysis for the Behavioral Sciences. 2nd ed. Academic Press, New York, NY.

DerSimonian, R., and N. Laird. 1986. Meta-analysis in clinical trials. Control. Clin. Trials 7:177-188.

Distl, O., and D. Schmid. 1994. Einfluss einer zufütterung von Biotin auf die Klauenform, -härte und -gesundheit bei Milchkuhen. Berl. Munch. Tierarztl. Wouchenscher 49:581-588.

Egger, M., and G. Davey Smith. 2003. Principles of and procedures for systematic reviews. Pages 23-42 in Systematic Reviews in Health Care Meta-Analysis in Context. M. Egger, G. Davey Smith, and D. G. Altman, ed. British Medical Journal Books, London, UK

Egger, M. G. Davey Smith, M. Schneider, and C. Minder. 1997. Bias in meta-analysis detected by a simple, graphical test. Br. Med. J. 315:629-634.

Enjalbert, F., M. C. Nicot, and A. J. Packington. 2008. Effects of peripartum biotin supplementation of dairy cows on milk production and milk composition with emphasis on fatty acids profile. Livest. Sci. 114:287-295

Ferreira, G., and W. P. Weiss. 2007. Effect of biotin on activity and gene expression of biotin-dependent carboxylases in the liver of dairy cows. J. Dairy Sci. 90:1460-1466.

Ferreira, G., W. P. Weiss, and L. B. Willett. 2007. Changes in measures of biotin status do not reflect milk yield responses when dairy cows are fed supplemental biotin. J. Dairy Sci. 90:1452-1459

Fitzgerald, T., B. W. Norton, R. Elliott, H. Podlich, and O. L. Svendsens. 2000. The influence of long-term supplementation with biotin on the prevention of lameness in pasture fed dairy cows. J. Dairy Sci. 83:338-344.

Frigg, M., D. Hartmann, and O. C. Straub. 1994. Biotin kinetics in serum of cattle after intravenous and oral dosing. Int. J. Vitam. Nutr. Res. 64:36-40.

Frigg, M., O. C. Straub, and D. Hartmann. 1993. The bioavailability of supplemental biotin in cattle. Int. J. Vitam. Nutr. Res. 63:122-128.

Ganjkhanlou, M., M. Salimi, A. Nikkhah, and A. Zali. 2007. Effect of supplemental dietary biotin on performance of Holstein dairy cows. Pak. J. Biol. Sci. 10:2960-2963.

Girard, C. L. 1997. B-Vitamins: Current recommendations are inadequate for optimal production. http://www.wcds.afns.ualberta.ca/ Proceedings/1997/ch08-97.htm.

Girard, C. L. 1998. B-Complex vitamins for dairy cows: A new approach. Can. J. Anim. Sci. 78(Suppl. 1):71-90.

Hagemeister, H., and W. Steinberg. 1996. Effects of a long-term dietary biotin administration on claw health in dairy cows. Proc. 19th Int. Symp. Disorders Bovine Digit, Jerusalem, Israel.

Hardy, R. J., and S. G. Thompson. 1998. Detecting and describing heterogeneity in meta-analysis. Stat. Med. 17:841-856.

Hedges, J., R. W. Blowey, A. J. Packington, C. J. O'Callaghan, and L. E. Green. 2001. A longitudinal field trial of the effect of biotin on lameness in dairy cows. J. Dairy Sci. 84:1969-1975.

Higgins, J. P. T., and S. G. Thompson. 2002. Quantifying heterogeneity in a meta-analysis. Stat. Med. 21:1539-1558.

Higgins, J. P. T., S. G. Thompson, J. J. Deeks, and D. G. Altman. 2003. Measuring inconsistency in meta-analysis. BMJ 327:557560 .

Higuchi, H., T. Maeda, M. Nakamura, A. Kuwano, K. Kawai, M. Kasamatsu, and H. Nagahata. 2004. Effects of biotin supplementation on serum biotin levels and physical properties of samples of solar horn of Holstein cows. Can. J. Vet. Res. 68:93-97.

Hochstetter, T. 1998. Horn quality of the bovine hoof under the influence of biotin supplementation. DVM Inaugural Dissertation. Journal \#2176. Free University of Berlin, Germany. 
Kluenter, A. M., W. Steinberg, and W. Schuep. 1993. Influence of biotin supplementation on the concentration of biotin in the blood plasma and milk of dairy cows. Roche Res. Rep. No. B-162-112. Roche Vitamins Inc., Parsippany, NJ.

Knapp, G., and J. Hartung. 2003. Improved tests for a random-effects meta-regression with a single covariate. Stat. Med. 22:26932710 .

Koester, A., K. Meyer, C. K. W. Mulling, J. R. Scaife, M. Birnie, and K. D. Budras. 2002. Effects of Biotin supplementation on horn structure and fatty acid pattern in the bovine claw under field conditions. Pages 263-267 in Proc 12th Int. Symp. Lameness Ruminants. J. K. Shearer, ed. Orlando, FL.

Lavori, P. W., and J. Kelsey. 2002. Introduction and overview (clinical trials). Epidemiol. Rev. 24:1-3.

Lean, I. J., A. R. Rabiee, T. F. Duffield, and I. R. Dohoo. 2009. Invited review: Use of meta-analysis in animal health and reproduction: Methods and applications. J. Dairy Sci. 92:3545-3565.

Lischer, C. H., A. Hunkeler, A. Geyer, and P. Ossert. 1996. The effect of biotin in the treatment of uncomplicated claw lesions with exposed corium in dairy cows. Proc. 9th Int. Symp. Dis. Bovine Digit, Jerusalem, Israel.

Lischer, C. J., U. Koller, H. Geyer, C. H. Mulling, J. Schulze, and P. Ossent. 2002. Effect of therapeutic dietary biotin on the healing of uncomplicated sole ulcers in dairy cattle - A double blinded controlled study. Vet. J. 163:51-60.

Majee, D. N., E. C. Schwab, S. J. Bertics, W. M. Seymour, and R. D. Shaver. 2003. Lactation performance by dairy cows fed supplemental biotin and a B-Vitamin blend. J. Dairy Sci. 86:2106-2112.

Midla, L. T., K. H. Hoblet, W. P. Weiss, and M. L. Moeschberger. 1998. Supplemental dietary biotin for prevention of lesions associated with aseptic subclinical laminitis (pododermatitis aseptica diffusa) in primiparous cows. Am. J. Vet. Res. 59:733-738.

Miller, B. L., J. C. Meiske, and R. D. Goodrich. 1986. Effects of grain source and concentrate level on B-vitamin production and absorption in steers. J. Anim. Sci. 62:473-483.

Milligan, L. P., J. M. Asplund, and A. R. Robblee. 1967. In vitro studies on the role of biotin in the metabolism of rumen microorganisms. Can. J. Anim. Sci. 47:57-64.

Mock, D. M. 2005. Biotin. Pages 189-207 in Modern Nutrition in Health and Disease. 10th ed. M. E. Shils, M. Shike, A. C. Ross, B. Caballero, R. L. Weinsier, R. J. Cousins, ed. Lippincott Williams \& Wilkins, Baltimore, MD.

Mülling, C. K. W. 2009. Nutritional influences on horn quality and hoof health. Adv. Dairy Technol. 21:283-291.

Mülling, C. K. W., H. H. Bragulla, S. Reese, K. D. Budras, and W. Steinberg. 1999. How structures in bovine hoof epidermis are influenced by nutritional factors. Anat. Histol. Embryol. 28:103-108.

Offer, J. E., D. N. Logue, N. W. Offer, and M. Marsden. 2004. The effect of concentrate composition on lameness and hoof health in dairy cows. Vet. J. 167:111-113.

Packington, A. 2004. Biotin for dairy cows. Society of Feed Technologists (UK), Ruminant Nutrition April 27, 2004.

Peters, J. L., A. J. Sutton, D. R. Jones, K. R. Abrams, and L. Rushton. 2008. Contour-enhanced meta-analysis funnel plots help distinguish publication bias from other causes of asymmetry. J. Clin. Epidemiol. 61:991-996.
Pötzsch, C. J., V. J. Hedges, R. W. Blowey, A. J. Packington, and L. E. Green. 2003. The impact of parity and duration of biotin supplementation of white line disease lameness in cattle. J. Dairy Sci. 86:2577-2582.

Rosendo, O., C. R. Staples, L. R. McDowell, R. McMahon, L. Badinga, G. C. Martin, J. F. Shearer, W. M. Seymour, and N. S. Wilkinson. 2004. Effects of Biotin supplementation on peripartum performance and metabolites of Holstein cows. J. Dairy Sci $87: 2535-2545$.

Sanchez, J., I. Dohoo, J. Carrier, and L. DesCoteaux. 2004. A metaanalysis of the milk-production response after anthelmintic treatment in naturally infected adult dairy cows. Prev. Vet. Med. 63:237-256.

Santschi, D. E., R. Berthiaume, J. J. Matte, A. F. Mustafa, and C. L. Girard. 2005a. Fate of supplementary B-vitamins in the gastrointestinal tract of dairy cows. J. Dairy Sci. 88:2043-2054.

Santschi, D. E., J. Chiquette, R. Berthiaume, R. Martineau, J. J. Matte, A. F. Mustafa, and C. L. Girard. 2005b. Effect of the forage to concentrate ratio on B-vitamin concentrations in different ruminal fractions of dairy cows. Can. J. Anim. Sci. 85:389-399.

Sarasin, A. 1994. An in vitro model for organotypic epidermal differentiation: Effects of biotin. DVM Thesis. University of Zurich, Switzerland.

Schwab, E. C., C. G. Schwab, R. D. Shaver, C. L. Girard, D. E. Putnam, and N. L. Whitehouse. 2006. Dietary forage and nonfiber carbohydrate contents influence B-vitamin intake, duodenal flow, and apparent ruminal synthesis in lactating dairy cows. J. Dairy Sci. 89:174-187.

Seymour, W. M. 2001. Biotin, Hoof Health and Milk Production in Dairy Cows. Pages 70-78 in Proc. 12th Annual Florida Ruminant Nutrition Symposium. Florida, USA.

Shearer, J. K. 2005. Nutrition and Claw Health. Tri-State Dairy Nutrition Conference. 1-10.

Socha, M. T., A. B. Johnson, and L. M. Schugel. 1999. The impact of parity and duration of biotin supplementation on white line disease lameness in dairy cattle. J. Dairy Sci. 86:2577-2582.

Steinberg, W., A. M. Kluenter, N. Bohn, C. Griggio, and W. Schuep. 1995. Biotin balance studies in dairy cows with and without biotin supplementation. Roche Res. Rep. No. B-164-549. Roche Vitamins Inc., Parsippany, NJ.

Thompson, S. G., and J. P. T. Higgins. 2002. How should metaregression analyses be undertaken and interpreted? Stat. Med. $21: 1559-1573$

Tomlinson, D., and M. Socha. Undated. Nutrition: Building the Bovine Claw. Accessed May 2010. http://www.hooftrimmers.org/ pdf/nutrition\%20and\%20bovine\%20claw.pdf.

Weiss, B. 2001. Effect of supplemental biotin on performance of lactating dairy cows. Accessed May 2010. http://dairy.osu.edu/resource/feed/biotinforweb.pdf.

Whitehead, C. C. 1988. Biotin in der Tierernährung. GrenzachWyhlen, Hoffman-La Roche, ACO Ltd., Basel, Switzerland..

Zimmerly, C. A., and W. P. Weiss. 2001. Effects of supplemental dietary biotin on performance of Holstein cows during early lactation. J. Dairy Sci. 84:498-506.

Zinn, R. A., F. N. Owens, R. L. Stuart, J. R. Dunbar, and B. B. Norman. 1987. B-vitamin supplementation of diets for feedlot calves. J. Anim. Sci. 65:267-277. 
Appendix

Table A1. List of studies excluded and reasons for exclusion

\begin{tabular}{ll}
\hline Study & Reason for exclusion \\
\hline Mülling et al. (1999) & No production or hoof health data \\
Weiss (2001) & Review \\
Tomlinson and Socha (undated) & Review \\
Offer et al. (2004) & Lameness in cattle \\
Abel et al. (2006) & No production or hoof health data \\
Bunge (2006) & No production or hoof health data \\
Lischer et al. (2002) & No production or hoof health data \\
Mülling (2009) & Review \\
Higuchi et al. (2004) & No production or hoof health data \\
Girard (1998) & Review \\
Shearer (2005) & Review \\
Seymour (2001) & Review \\
Midla et al. (1998) & Digit data \\
Girard (1997) & No data \\
Socha et al. (1999) & Review \\
Packington (2004) & Review \\
Distl and Schmid (1994) & German language \\
Campbell et al. (2000) & Beef \\
Majee et al. (2003) & $4 \times 4$ Latin square design \\
Ganjkhanlou et al. (2007) & Crossover design \\
Ganjkhanlou et al. (2007) & Crossover design \\
Ferreira and Weiss (2007) & Crossover design \\
\hline
\end{tabular}

